\title{
Anti-CD73 Monoclonal Antibody TJ4309
}

National Cancer Institute

\section{Source}

National Cancer Institute. Anti-CD73 Monoclonal Antibody T/4309. NCI Thesaurus. Code C159168.

A humanized monoclonal antibody targ eting the ectoenzyme 5'-ecto-nucleotidase (cluster of differentiation 73; CD73; 5'-NT; ecto-5'-nucleotidase; NT5E), with potential immunomodulating and antineoplastic activities. Upon administration, anti-CD73 monoclonal antibody TJ4309 targets and binds to CD73 on tumor cells, thereby inhibiting CD73 activity. This prevents CD73-mediated conversion of extracellular adenosine monophosphate (AMP) to adenosine, preventing adenosine-mediated suppression of lymphocyte activity and increasing the activity of cytotoxic T-lymphocytes (CT Ls). This also activates macrophages and reduces the activity of both myeloid-derived suppressor cells (MDSCs) and regulatory T-lymphocytes (Tregs). By abrogating the inhibitory effect on the immune system and enhancing the CT L-mediated immune response against cancer cells, tumor cell growth is decreased. CD73, a plasma membrane protein belonging to the 5'-nucleotidase (NT ase) family, is upregulated on a number of cancer cell types and catalyzes the conversion of extracellular nucleotides, such as AMP, to membrane-permeable nucleosides, such as adenosine; it plays a key role in adenosinemediated immunosuppression within the tumor microenvironment (TME). 